for medical science (Engel, 1980), and our Patron has drawn attention to potentially additional dimensions of spiritual, ecological, and perhaps even political influences on the human psyche and its manifestations. The variety and complexity of these influences is a source of both wonder and frustration; it is the nature of science to attempt to reduce phenomena to their fundamentals, and the recent surge of interest in neurobiology holds much promise for the alleviation of mental suffering. However, no therapeutically significant achievements have as yet been realised from this approach and it would be foolish to replace an historical overzealous application of psychoanalytical theories with a similarly extreme, premature bias towards the biological in psychiatry.

The Prince warns of the implications of our medical model and materialistic viewpoint towards mental illness and psychiatric training. We should remember that medical training distances us from emotional involvement with patients (the lay sense of the word 'clinical' is of a cold, detached attitude) which is reinforced by an increasing reliance on drug treatments. The dictates of time, pressure of work and shortage of resources discriminate against the time-consuming psychotherapies which can affect a more meaningful and longer-term benefit for the patient. The need for trainees to produce research publications impels them to undertake brief, often ill-conceived and ultimately inconsequential, shortsighted projects with a view to personal gain through promotion. Biological studies are appealing to psychiatrists at all stages of their careers as they tend to attract greater funding, demand fewer numbers of subjects, and are quicker to conduct than those of a psychosocial orientation - important factors when one considers the 'publish or perish' phenomenon where quantity is often valued over quality. Such strong motivators, the medical hierarchial career structure, and the need to emulate our mentors all encourage the expression of a simplistic biological reductionism that could skew our training and clinical practice, and may even hinder further development in the understanding of psychiatric conditions and their treatment. Continued research is essential in advancing the frontiers of our knowledge, but we must bear in mind that up to three-quarters of the scientific literature may be worthless (Hamilton, 1990) and conventional limits of statistical significance are arbitrarily determined.

His Royal Highness sees the future of psychiatry in the community and in prevention. We must retain a flexibility and balance in our approach, or we risk losing ground to other professionals and nonstatutory agencies; even our raison d'etre (Lancet,
1985). Unless we are to ignore the vast majority of emotional distress and psychological disorder we shall have to be adept in counselling and psychotherapeutic skills, or at least the supervision of them. It is of concern that there are no requirements for psychotherapeutic experience during our training. Our conceptions of psychiatric illness are city and institution based, where people can easily be depersonalised and dehumanised. We should remember that we are employed to provide a service to our patients. To return them to their GP with the comment "no formal psychiatric illness discharge" is a dismissive, unhelpful practice to be condemned. The vagaries of the human condition are such that it is unlikely we shall ever be able to sharply demarcate distress from illness, however defined.

To be provocative: I wonder how much biological psychiatry is a determined attempt to enhance credibility with our medical colleagues or to remove us from scientific and political controversy surrounding social issues, how different things might be if even some of the vast expenditure on drugs and research in the past thirty years had been invested in combating social adversity, how ecologically damaging the processes and effects of drug manufacture are, and whether psychiatrists should be more overtly political in challenging the effects of social deprivation on mental health. To my mind our male-dominated, scientific, mechanistic view of mental illness needs to include a more feminine, subjective and sensitive aspect.

ENGEL, G. L. (1980) The clinical application of the biophsychosocial model. American Journal of Psychiatry, 137, 535-544.

Hamilton, D. P. (1990) Publishing by-and for?-the numbers. Science, 250, 1331-1332.

LANCET (1985) Psychiatry - discipline that has lost its way. Lancet, $i$ $731-732$.

Royal Edinburgh Hospital Edinburgh EHIO SHF

STEPHEN M. LAWRIE

\section{Use of fluoxetine in heroin addiction}

SIR: A priority in the treatment of heroin addiction is the prevention of relapse (Guelfi \& Trampetti, 1989). The use of opiate antagonist drugs has been advised to control relapse, following Wikler's 'deconditioning' theory (Wikler, 1974). Unfortunately, the results obtained by opiate antagonists are unsatisfactory and many patients discontinue treatment and continue with heroin. Only patients who have strong personal motivation show positive results with this method (Greenstein et al, 1976). 
The poor clinical results with the use of antagonist may be due to the continuation of 'craving'; modifcation of this could improve compliance and reduce the risk of relapse.

Fluoxetine has been demonstrated to act as an 'anti-craving' drug substitute for amphetamines in animals and man, and for alcohol in man (Murphy $e t$ $a l, 1988)$. There have also been positive results in the reduction of cocaine used by Methadone Maintenance Treatment Program (MMTP) patients (Pollack \& Rosenbaum, 1991).

Our observation regarding nine consecutive patients (seven males and two females: mean age 26 years, s.d. 3 years), all attenders at the Treatment Centre of Drug Addiction of the Psychiatric Clinic at Pisa University, corroborates these data. The patients have been treated with naltrexone plus fluoxetine, and their response to the treatment has been compared with the first nine consecutive patients, attending at the same out-patient unit who were treated only with naltrexone. Only one patient treated with naltrexone combined with fluoxetine relapsed, compared with five patients treated only with naltrexone $\left(\chi^{2}=4.00 ; P=0.045\right)$.

All patients met DSM-III-R criteria for heroin dependence; the severity of the illness was rated from mild to moderate. Patients were considered satisfactory responders if they remained off heroin and if they were well-adjusted socially three months after the start of the treatment. Medical examinations were performed every month. Case histories of drug addiction and social adjustment were evaluated by means of rating scales; they showed no significant differences between the two groups at the initiation of the treatment.

Only the MMTP patients usually achieve a program retention rate, after three months followup, comparable with our results. Fluoxetine may therefore reduce the craving which is the Achilles' heel of this condition.

Our criteria for selecting patients for treatment with antagonists are very strict. Nevertheless, combining this with fluoxetine in these patients appears to improve outcome. The efficacy of the naltrexonefluoxetine combination needs to be confirmed by double-blind controlled trials.

Greenstein, R. A., O'Brien, C. P., Mintz, J., et al (1976) Clinica experience with naltrexone in a behavioural research study. In Narcotic Antagonists: Naltrexone. Progress Report. NIDA Research Monograph 9 (eds J. Demetrios \& P. Renault), pp. 141-149. Rockville: NIDA.

Guelfi, G. P. \& TRAMPETT, R. (1989) II Naltrexone nella terapia dei tossicidipendenti: problemi e risultati. In Il Naltrexone nel trattamento medico, psicologico e sociale del tossicodipendente (eds G. P. Guelfi \& N. Piersantelli), pp. 41-53. Milan: Boehringer Mannheim, Italia.
Murphy, J. M., Waller, M. B. \& Gatto, G. J. (1988) Effects of fluoxetine on the intragastric self-administration of ethanol in the alcohol preferring $P$ line of rats. Alcohol, 5, 283-286.

Pollack, M. H. \& Rosenbaum, J. F. (1991) Fluoxetine treatment of cocaine abuse in heroin addicts. Journal of Clinical Psychiatry, 52, 31-33.

WIKLER, A. (1974) Requirements for extinction of relapsefacilitating variables for rehabilitation in a narcotic-antagonistic treatment program. In Narcotic Antagonists. Advances in Biochemical Psychopharmacology (eds M. C. Broude, L. S. Harris, E. L. May, et al). New York: Raven Press.

ICRO MAREMMANI

Psychiatric Clinic

PaOlo CastrogiovanNi

Pisa University

Via Roma 67

56100 Pisa

Italy

\section{Drug Addiction Fellowship}

LAURA DainI

OrIeTta ZolesI

\section{Cagliari 4 Pisa University}

\section{Violence on an acute ward}

SIR: Violence is a serious problem for those working in the health service (DHSS, 1988) and is commonly encountered in caring for the mentally ill, particularly in the hospital setting (James et al, 1990). This investigation was prompted by an apparent increase in the number of violent incidents on an acute admission ward.

This study was carried out in a 30-bed acute admission ward in the psychiatric wing of a district general hospital. The following data were examined retrospectively for the $\mathbf{4 8}$ months from January 1986 to December 1989 , using a validated methodology described by James et al (1990). The number of incidents of physical violence was recorded by the nurses (categorised according to whether the violence was directed at staff, patients, or property).

Over the four-year study period, 456 violent incidents were recorded. Violence against staff $(n=270,59 \%)$ and against other patients $(n=119$, $28.4 \%$ ) ranged from biting to punching. Those against property $(n=56,12 \%)$ consisted of destruction of furniture, fabric, and fittings; 11 incidents did not fit into any of the three subgroups. The level of violence increased ten-fold over the study period from 24 to 224 violent incidents per year $\left(\chi^{2}=220\right.$, d.f. $=3, P<0.001)$. Similarly, the three subgroups of violence also increased: violence against patients $\left(\chi^{2}=67.9\right.$, d.f. $\left.=3, P<0.001\right)$, violence against staff $\left(\chi^{2}=143.4\right.$, d.f. $\left.=3, P<0.001\right)$ and violence against property $\left(\chi^{2}=16\right.$, d.f. $\left.=3, P<0.005\right)$.

The level of violence, with 456 incidents, is very high. Furthermore, there was an alarming increase in 